3. 3D моделирование в компьютерных программах. [Электронный ресурс]. URL: http://www.interface.ru/home.asp?a rtId=29504 (дата обращения 26.03.2017).

\title{
Имитационное моделирование работы системы автосервиса средствами программы AnyLogic
}

Дулина Я.Р., студентка, Технический институт (филиал) Северо-Восточного федерального университета, 2. Нерюнгри E-mail: yana.dulina2017@yandex.ru

Научный руководитель: старший преподаватель Юданова В.В.

Системы массового обслуживания (далее СМО) в жизни человека встречаются ежедневно. Примерами таких систем являются очереди в банках, библиотеках, больницах, а также обслуживание в билетных кассах, автозаправках и т.п. Одним из более эффективных методов исследования данных процессов представляет метод имитационного моделирования (далее ИМ), которое поднимает моделирование на значительно более качественный и высокий уровень. ИМ (компьютерное моделирование) - это разновидность моделирования, которая реализуется с помощью специальных технологий программирования и имитирующих компьютерных программ. Целью ИМ является создание модели, которая будет имитировать какой-то процесс, и вычисление характеристик модели для получения статистических данных использования ресурсов системы. Одним из популярных программных продуктов для создания имитационных моделей является AnyLogic.

Программа AnyLogic обладает удобным, современным интерфейсом и позволяет использовать язык программирования Java при разработке имитационных моделей. Данный продукт поддерживает три вида имитационного моделирования: агентное, дискретно - событийное, системная динамика. B системy AnyLogic встроены следующие стандартные библиотеки для облегчения процесса моделирования: библиотека дорожного движения, библиотека моделирования процессов, железнодорожная и пешеходная библиотека. Кроме того, инструментарий программы позволяет создавать интерактивную анимацию моделей в 2D и 3D формах [1].

Перед созданием имитационной модели необходимо выполнить постановку решаемой задачи. В качестве объекта изучения выбран автосервис ООО «Диагностика». При проведении ремонтных работ в автосервисе используется четыре бокса - в первом боксе применяют старое техническое оборудование, в остальных трех боксах - новое техническое оборудование. Необходимо промоделировать работу автосервиса с выполнением следующих условий.

Интервал времени между автомашинами приезжающими в автосервис должен регулироваться пользователем. Распределение автомашин в боксы происходит с вероятностью 0.4 и 0.6 (боксы с новым оборудованием пользуются большим спросом, чем боксы со старым оборудованием). Среднее время обслуживания автомашин подчиняется экспоненциальному закону распределения, и также должно 
устанавливаться пользователем. Необходимо промоделировать работу автосервиса в течение 480 минут реального времени. Обеспечить сбор статистики данных о работе CMO: средняя занятость боксов со старым и новым оборудованием, средняя длина очереди и среднее время клиентов в системе. Реализовать 3D анимацию модели, выполнить эксперимент по оптимизации (определить оптимальное количество ресурсов - боксов).

В основе решения данной задачи использована дискретно - событийная модель, которая представляет собой хронологическую последовательность событий. Создание дискретно - событийной модели в программе AnyLogic осуществляется в виде диаграммы процесса с использованием библиотеки моделирования процессов. Первым блоком построенной диаграммы является генератор заявок - source, который моделирует прибытие водителей в автосервис. Поступление заявок настроено согласно экспоненциальному закону распределения. Далее следуют: объект selectOutput, который является блоком принятия решения - в зависимости от заданной вероятности поступившие заявки (автомашины), распределяются между двумя выходными портами; queue - моделирует очередь прибывших машин; delay - служит для обозначения бокса со старым техническим оборудованием и моделирует задержку агентов на заданный период времени; service - служит для обозначения боксов с новым техническим оборудованием и моделирует захват для агента заданного количества ресурсов, задержку агента, а затем освобождение захваченных ресурсов; resourcePool - задает ресурсы определенного типа (три бокса с новым техническим оборудованием). Объект sink уничтожает поступивших агентов и используется в качестве конечной точки потока агентов и диаграммы процесса (рис.1).

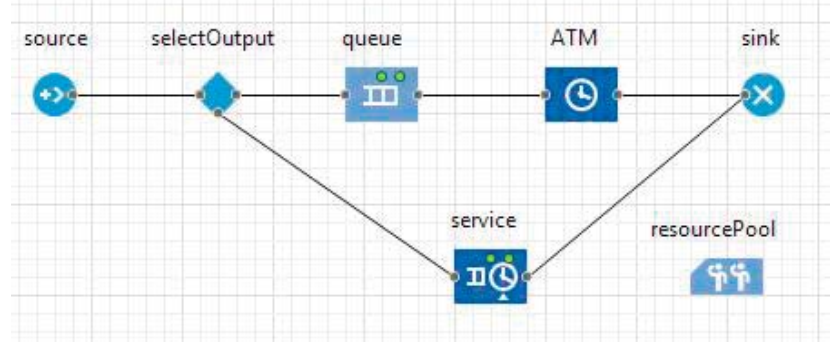

Рис. 1. Диаграмма процесса

В стартовой панели запуска эксперимента Simulation размещены текстовые поля и бегунки для возможности изменения интенсивности прибытия клиентов в единицу времени, количества ресурсов - боксов с новым оборудованием, и времени обслуживания (на новом и старом оборудовании) (рис.2). Эксперимент Simulation поддерживает один из двух режимов эксперимента с моделью. Первый режим виртуального времени, где единица модельного и физического времени не совпадают, второй режим реального времени, при котором задается связь физического времени с модельным временем. Модель автосервиса будет выполняться в режиме реального времени и остановится, когда время достигнет 480 мин. 


\section{Автосервис}

\section{Запустить}

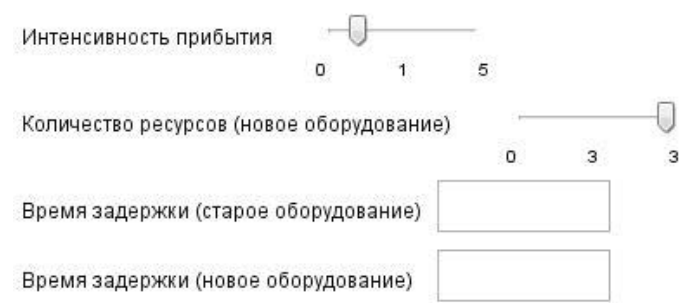

Рис. 2. Стартовая панель для настройки эксперимента Simulation

Программный продукт AnyLogic предоставляет удобные средства для сбора статистики работы моделируемой системы. Сбор статистических данных о работе автосервиса представлено с помощью столбиковых диаграмм для отображения интересующих статистических характеристик: среднее время клиентов в системе, средняя длина очереди к новому и старому оборудованию, средняя занятость старого и нового оборудования (рис.3). В качестве единиц модельного времени используются минуты.
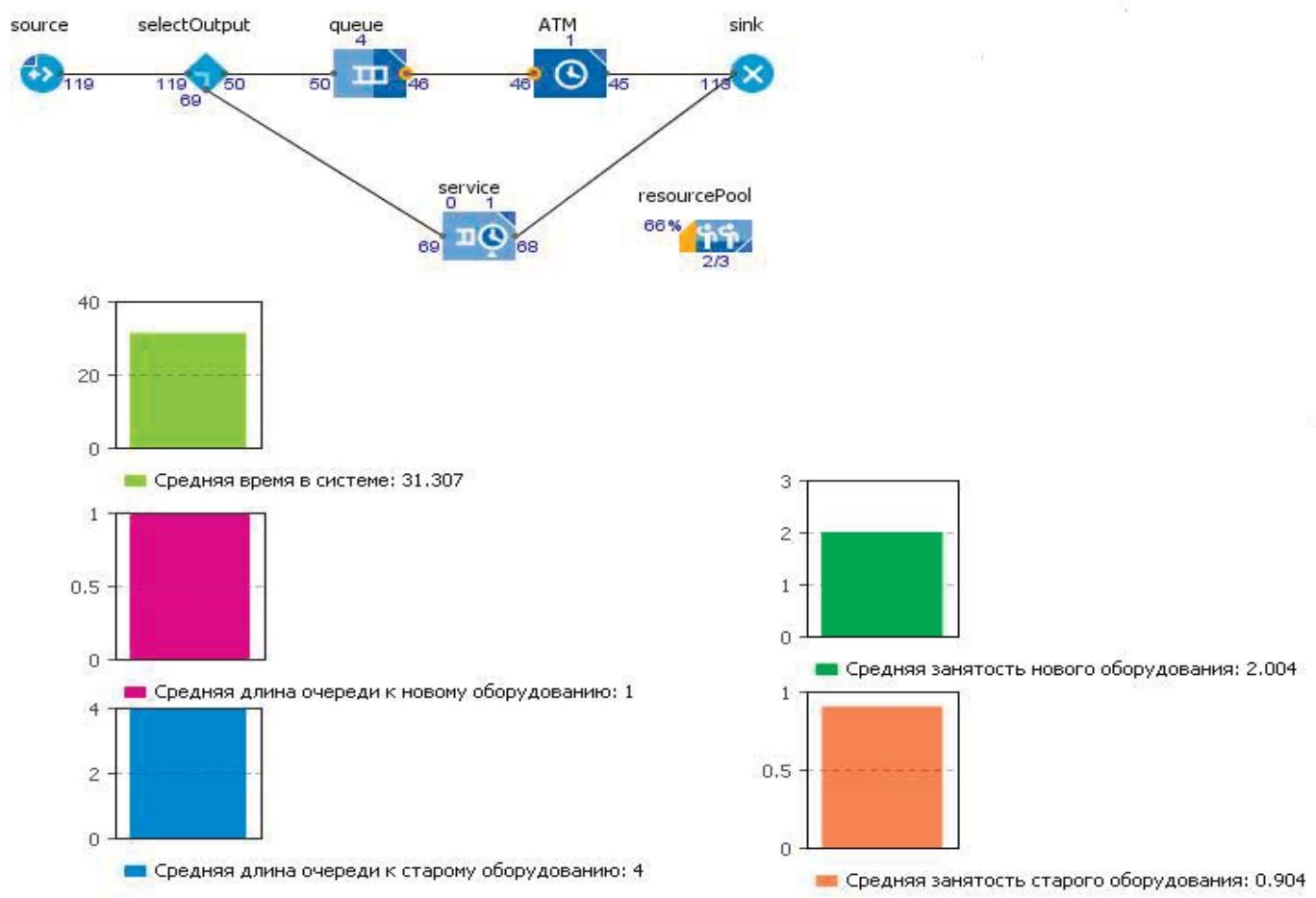

Рис. 3. Результат работы модели

Для визуализации работы автосервиса в AnyLogic использованы инструменты 3D анимации, которые включают в себя множество готовых 3D объектов. При создании анимации использованы элементы палитры разметки пространства, такие как точечный узел, обозначающий первый бокс, путь, обозначающий очередь к боксу, прямоугольные узлы - обозначение мест ожидания и обслуживания автомашин и месторасположения обслуживающего персонала (слесарей). Так же в модель добавлены новые агенты для 3D анимации изображений автомашин, обслуживающего персонала (слесарей) и помещений-боксов для ремонта автомобилей. Готовая 3D 
анимация является реалистичным и наглядным методом визуализации моделируемого процесса (рис.4).

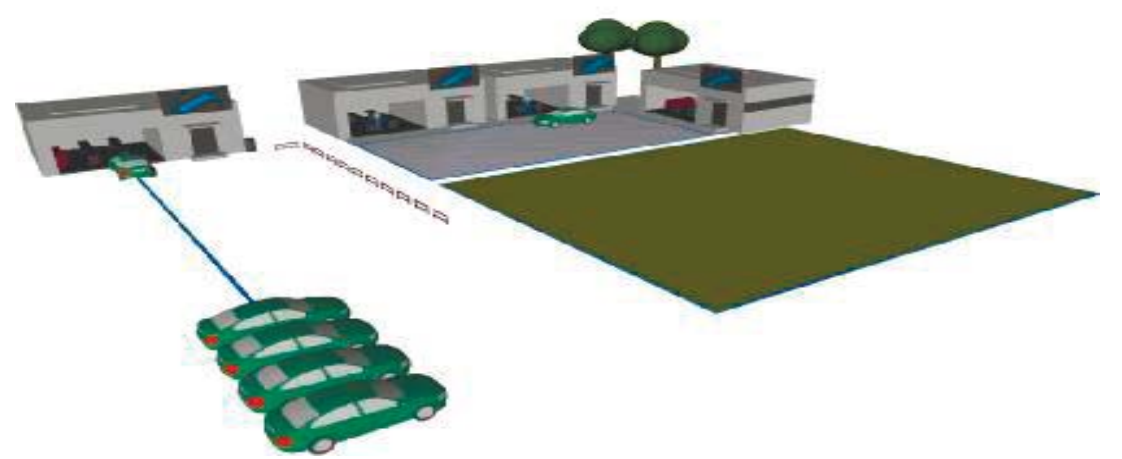

Рис. 4. 3D анимация модели

Для изучения поведения модели воспользуемся инструментами оптимизации, встроенными в системy AnyLogic. Выполним поиск минимального количества ресурсов (боксов) при соблюдении требования, что средний размер очереди не должен превышать пяти автомашин. В рабочей области эксперимента Optimization так же разместим бегунок и текстовые поля для возможности изменения входных данных, таких как интенсивность прибытия машин и времени задержки (обслуживания на новом и старом оборудовании). Оптимизационный эксперимент построен на поиске статистически оптимального значения исследуемого параметра в результате большого количества прогонов модели (100 итераций) (рис.5). Окно презентации результатов эксперимента содержит: график - который показывает зависимость динамики изменения значений параметра N - количество боксов с новым оборудованием от номера итерации, таблицу значений входных параметров, которые участвуют в оптимизации $\mathrm{w}$ - время обслуживания в боксе с новым оборудованием, w1 - время обслуживания в боксе со старым оборудованием, Lambda - интенсивность прибытия машин. На графике справа отображена зависимость значений оптимизируемого параметра от номера итерации (одна итерация - одно выполнение эксперимента при определенных значениях “перебираемого” параметра N). Красным отображено лучшее недопустимое значение, т.е. значение, полученное без учета ограничений, наложенных на оптимизируемую модель, а синим - лучшее допустимое. С увеличением количества итераций значение оптимизируемого параметра стремится к двум. Это же значение можно увидеть в окне слева от графика. Из этого делаем вывод, что для заданных нами начальных условий w, w1, Lambda наименьшее возможное количество боксов будет равно двум.

Таким образом, построенная имитационная модель для исследования работы системы автосервиса, на примере ООО «Диагностика», позволяет: найти оптимальное решение задачи, узнать интересующую нас статистику, изменять исходные данные перед запуском модели, наглядно с помощью 3D моделирования увидеть работу системы. Построенная модель является одним из примеров основ ИМ СМО. Имитационное моделирование является отличным методом для моделирования производственных процессов, оно более точно и наглядно показывает поведение модели и ее характеристик. 


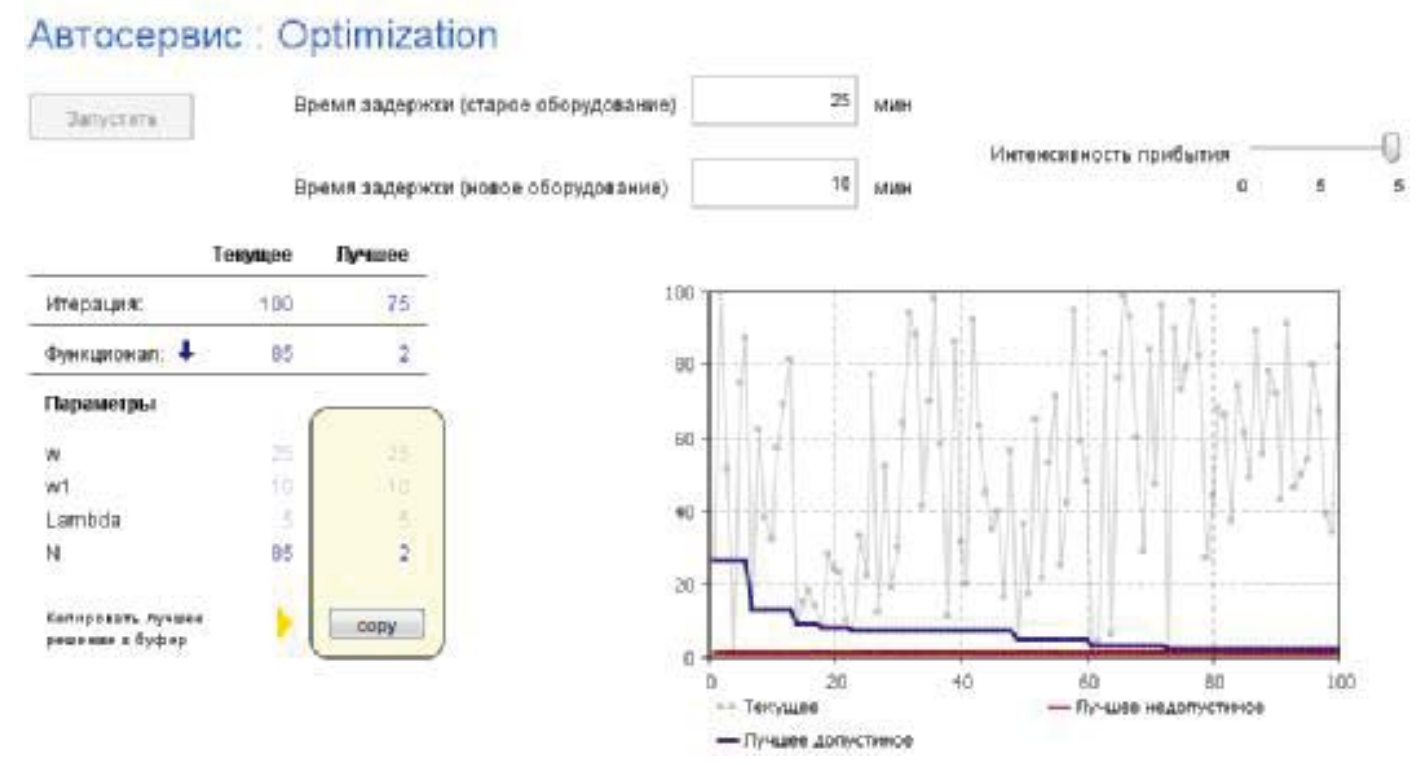

Рис. 5. Эксперимент по оптимизации

Список литературы

1. Куприяшкин,А.Г. Основы моделирования систем: учеб. пособие / А.Г. Куприяшкин; Норильский индустр. ин-т. -Норильск: НИИ, 2015.- С. 13-16.

\section{Подвижная платформа с пушкой гаусса под управлением Arduino}

Еремин Д.А., ученик, МОУ Информационно-технологический лицей №24, 2. Нерюнгри

Научные руководители: учитель робототехники Дёминов С.И., педагог дополнительного образования Миколайчук В.А.

Прототипом будущей платформы послужила самая известная на сегодняшний день, устрашающая и не имеющая аналогов на сегодняшний день платформа Армата. Универсальная боевая платформа «Армата»- тяжёлая гусеничная платформа, разработанная Урал вагон заводом. Широкой публике изделия на базе платформы были представлены на параде Победы в 2015 году.

Именно после изучения Универсальной боевой платформы «Армата» пришла в голову идея создания универсальной гусеничной платформы для разработки будущих проектов управляемых роботов. как и в проекте Армата, было решено использовать одну универсальную систему управления которую также можно модернизировать под конкретные задачи будущего робота.

На сегодняшний день существует множество различных способов управления роботами и не всегда есть возможность их использовать. Использование плат Arduino в качестве универсального инструмента управления существенно упрощает создание новых интересных проектов.

Arduino - это электронный конструктор и удобная платформа быстрой разработки электронных устройств для новичков и профессионалов. Платформа 